\title{
Consistent nest-site selection across habitats increases fitness in Asian Houbara
}

\author{
João L. Guilherme, ${ }^{1 *}$ Robert J. Burnside, ${ }^{1}$ Nigel J. Collar, ${ }^{2}$ and Paul M. Dolman ${ }^{1}$ \\ 1 School of Environmental Sciences, University of East Anglia, Norwich, UK \\ 2 BirdLife International, Cambridge, UK \\ * Corresponding author: joaolguilherme@gmail.com \\ Submitted August 11, 2017; Accepted November 13, 2017; Published January 24, 2018
}

\begin{abstract}
Nest-site choice profoundly influences reproductive success and the survival of incubating adult birds. Asian Houbara (Chlamydotis macqueenii) nest in subtly contrasting habitats where the main cause of nest failure is predation. We examined nest-site selection across 3 semiarid shrub habitats that differed in vegetation structure and hypothesized that increased concealment would reduce nest predation. We quantified vegetation structure at 210 nests and 194 random control sites at 2 scales, the "nest area" (50 m radius, considering mean "shrub height" and mean "shrub frequency") and "nest scrape" (2 m radius, considering a "concealment index"). Variance ratio tests showed that variance in both shrub height and concealment index was lower at nests than at random sites, indicating nonrandom selection. Analysis of the probability of nest occurrence for nest area indicated consistent selection of intermediate shrub heights (shrub height + shrub height ${ }^{2}$ ) in the Astragalus, Salsola arbuscula, and S. rigida shrub assemblages $(29.5-31.5 \mathrm{~cm})$, although this was not supported statistically in S. rigida because the vegetation available was already similar to the optimal structure. Nest survival analysis, controlling for date, showed that shrub height (but not its quadratic term) in the nest area reduced nest predation rate. Females likely traded off nesting in even taller shrubs that may confer greater nest success against the ability to see approaching danger and thus to reduce the risk of being depredated themselves (head height during vigilance when incubating is $\sim 30 \mathrm{~cm}$ ), given that we have no records of females being depredated on the nest. At the nest scrape, females strongly selected better-concealed locations, although the concealment index did not affect nest success. We suggest that concealing the scrape among shrubs may have other roles, such as thermoregulation.
\end{abstract}

Keywords: Chlamydotis macqueenii, nest placement, nest predation, nest success, nest survival, predation risk, vegetation structure, visual security

\section{Une sélection du site de nidification consistante entre les habitats augmente la valeur adaptative chez Chlamydotis macqueenii \\ RÉSUMÉ}

Le choix du site de nidification influence profondément le succès reproducteur et la survie des adultes en incubation. Chlamydotis macqueenii niche dans des habitats subtilement contrastés où la prédation est la principale cause d'échec de la nidification. Nous avons examiné la sélection du site de nidification dans trois habitats arbustifs semi-arides qui différaient dans la structure de la végétation. Nous avons émis l'hypothèse qu'une dissimulation accrue du nid réduit la prédation. Nous avons quantifié la structure de la végétation à 210 nids et 194 sites témoins aléatoires à deux échelles, soit la «zone de nidification » (rayon de $50 \mathrm{~m}$, considérant une « hauteur des arbustes » moyenne et une «fréquence des arbustes » moyenne) et la « dépression de nidification » (rayon de $2 \mathrm{~m}$, considérant un « indice de dissimulation »). Les tests de ratio des variances ont montré que les variances de la hauteur des arbustes et de l'indice de dissimulation étaient plus faibles pour les nids que pour les sites aléatoires, ce qui indique une sélection non aléatoire. L'analyse de la probabilité de présence d'un nid pour la zone de nidification indiquait une sélection consistante d'arbustes de hauteur intermédiaire (hauteur des arbustes + hauteur des arbustes ${ }^{2}$ ) dans les assemblages arbustifs d'Astragalus, Salsola arbuscula et $S$. rigida $(29,5-31,5 \mathrm{~cm})$, bien que cela ne soit pas confirmé statistiquement chez $\mathrm{S}$. rigida car la végétation disponible était déjà similaire à la structure optimale pour la nidification. En contrôlant pour la date, l'analyse de la survie des nids a montré que la hauteur des arbustes (mais pas son terme quadratique) dans la zone de nidification réduit le taux de prédation des nids. Les femelles ont apparemment échangé une nidification dans des arbustes plus grands, qui peuvent conférer un plus grand succès de nidification, contre la capacité de voir approcher le danger et donc la réduction du risque de prédation sur elles-mêmes (la hauteur de la tête en vigilance lors de l'incubation est $\sim$ $30 \mathrm{~cm}$ ), puisque nous n'avons pas eu de cas de femelles ayant subi de la prédation sur le nid. Dans la dépression de nidification, les femelles sélectionnaient fortement des sites mieux dissimulées, bien que l'indice de dissimulation n'ait 
pas affecté le succès de nidification. Nous suggérons que le fait de dissimuler la dépression du nid dans les arbustes peut avoir d'autres rôles, comme la thermorégulation.

Mots-clés : Chlamydotis macqueenii, emplacement du nid, prédation des nids, risque de prédation, sécurité visuelle, succès de nidification, structure de la végétation, survie des nids

\section{INTRODUCTION}

Choosing where to nest may influence avian reproductive success and, ultimately, the survival of the incubating adult. Although other factors, such as food availability (Newton 1991), thermoregulation (Yanes et al. 1996), or environmental predictability (Conover et al. 2010), may constrain nest-site selection as the primary cause of nest failure, nest predation has long been considered the main factor driving nest-site selection in birds (Lack 1968, Martin 1993, Ibáñez-Álamo et al. 2015). Where incubating adults are also themselves at particular risk of predation, avoidance of habitat features that impede vision may also be important in determining nest site, as seen in groundnesting birds breeding in open habitats (e.g., Magaña et al. 2010, Webb et al. 2012). Because the needs for concealment and a clear view for visual security (i.e. the ability of the incubating bird to observe potential danger at a large enough distance to allow it to escape) may conflict (Camp et al. 2013), birds may potentially trade off these requirements when selecting a nest site (Götmark et al. 1995, Lloyd 2004, Miller et al. 2007, Magaña et al. 2010).

While many bird species find suitable nesting conditions across different habitats (e.g., Skeel 1983), the availability and quality of nest sites (Johnson 2007) may differ between habitats as a result of varying ecological constraints (e.g., the range of vegetation structure available; Scott et al. 2002). Understanding whether, and how, nest-site selection varies between habitats may help inform effective management and conservation efforts. Furthermore, relating nest-site selection to nest survival is crucial for understanding whether observed patterns influence individual fitness (Clark and Shutler 1999), although studies to date have shown inconsistent results (see Chalfoun and Schmidt 2012, Borgmann and Conway 2015).

Throughout its breeding range, the cryptic, groundnesting Asian Houbara (Chlamydotis macqueenii; IUCN status "vulnerable"; BirdLife International 2016) nests in a variety of shrub assemblages that are mostly used as rangelands; males play no role in the nesting process beyond fertilizing females, which are therefore exclusively involved in nest-site selection. The nest is simply a slight (if any) indentation ("scrape") in the ground involving no material and typically placed in sites with good visibility and sparse vegetation (Yang et al. 2003). We examined nest-site selection by the Asian Houbara, and the consequences of such choices for nest survival, across a heterogeneous semiarid landscape of the Kyzylkum Desert in Uzbekistan. We compared vegetation structure at nest sites and random control sites across 3 semiarid shrub assemblages, considering 2 scales: the surrounding "nest area" (50 m radius) and the immediate "nest scrape" (2 m radius), each of which may independently influence female choices. We tested the hypotheses that females select similar vegetation structures at nest sites across different shrub assemblages and that selection for features that improve concealment will positively influence nest survival through avoidance of nest predation.

\section{METHODS}

\section{Study Area}

Our study area covered $\sim 14,300 \mathrm{~km}^{2}$ of the southern Kyzylkum Desert, in the Bukhara District of Uzbekistan $\left(39.34-40.56^{\circ} \mathrm{N}, 62.21-65.20^{\circ} \mathrm{E}\right)$. The climate is predominantly arid and continental, characterized by hot summers and cold winters, with annual precipitation of 125-170 $\mathrm{mm}$ falling mostly during winter as snow, or in spring, often as heavy showers. Lying at 170-400 m above sea level, the landscape was largely flat with gently rolling terrain, bordered to the north and east by low mountains, to the west by large sand dunes dominated by white saxaul (Haloxylon persicum) sub-forest, and to the southeast by irrigated croplands and villages (Koshkin et al. 2016a). The area was characterized by a mosaic of semiarid desert shrub assemblages comprising halophytic and droughtresistant shrubs, and the local species composition was influenced by topography, geomorphology, drainage, and soil.

The distribution of 5 shrub assemblages was previously classified and mapped, through extensive field survey (871 sampling locations; see Koshkin et al. 2016a, 2016b), as "Salsola rigida," dominated by 2 saltwort species, S. rigida and S. gemmascens, on halophytic soils $\left(2,180 \mathrm{~km}^{2}\right)$; "Salsola arbuscula," characterized by high densities of this taller saltwort species, but also Artemisia diffusa and $S$. rigida, on gypseous and halophytic soils $\left(3,904 \mathrm{~km}^{2}\right)$; "Astragalus," categorized by the leguminous Astragalus villosissimus, with Convolvulus hamadae and Salsola spp., on semi-consolidated sands $\left(3,778 \mathrm{~km}^{2}\right)$; "Artemisia," largely dominated by $A$. diffusa, typical of gypseous or clay soils at slightly higher elevations $\left(2,873 \mathrm{~km}^{2}\right)$; and "Calligonum," comprising both Calligonum microcarpum and C. leucocladum and a high frequency of A. villosissimus and C. hamadae, characteristic of drifting and weakly consolidated sands $\left(1,603 \mathrm{~km}^{2}\right)$. 
Pastoralism, with areas of desert used as rangeland during spring for flocks mainly of sheep (Koshkin et al. 2014), varied at the landscape scale, because it was constrained by proximity to water sources (particularly functioning wells) and roads, with most sheep camps found within $10-20 \mathrm{~km}$ of croplands and settlements, leaving considerable areas of desert free of grazing pressure (Koshkin et al. 2014). Although degraded areas were noted around water points and sheep camps, at the landscape scale even moderate (10-30 individuals $\mathrm{km}^{-2}$ ) to high (30-83 individuals $\mathrm{km}^{-2}$ ) sheep densities had little impact on shrub vegetation structure (Koshkin et al. 2014), nor did they affect Asian Houbara clutch size, nest success, or egg hatchability (Koshkin et al. 2016b). Therefore, when modeling nest-site selection and nest survival, we did not include measures of sheep density, focusing solely on vegetation structure.

\section{Nest Searches and Monitoring}

Asian Houbara nests were found by tracking female footprints and monitoring satellite-tagged birds. Searches were conducted during 5 breeding seasons (earliest laying date: March 7; latest laying date: May 7) from 2012 to 2016, in areas known to hold females, across a variety of substrates (consolidated sand, weakly consolidated sand and clay) within the 5 shrub assemblages, including areas with high and low sheep densities (Koshkin et al. 2016b). However, in the hard clay substrates of the Artemisia shrub assemblage, our main nest-searching method, following tracks, was of limited use, and in Calligonum our nestsearching ability was reduced by higher densities of sheep and the presence of large shrubs and small dunes; therefore, these 2 shrub assemblages were excluded from analyses, owing to low sample size.

Female tracks were searched for by 2 observers from a vehicle driven at a precautionary low speed $\left(5-10 \mathrm{~km} \mathrm{hr}^{-1}\right)$ in order to reduce the risk of flushing females directly off the nest at close range, which can have negative effects on nest survival (Koshkin et al. 2016b). Searches were confined to the $2-3 \mathrm{hr}$ after sunrise and before sunset, to reduce the risk of exposing eggs to high temperatures. Whenever Asian Houbara tracks were found, they were followed for a few hundred meters. If a nest was not found after $\sim 30$ min the tracking was stopped, to avoid keeping a female off her nest too long (data from nest cameras indicated that females take incubation breaks of $\sim 30 \mathrm{~min}$; R. J. Burnside personal observation). For 27 wild females carrying satellite transmitters as part of a tagging program (under license from the State Committee for Nature Conservation of the Republic of Uzbekistan; see Burnside et al. 2017), GPS location data (accuracy $\pm 18 \mathrm{~m}$ ) were inspected daily; if a female had $\geq 2$ repeat fixes from the same location, the area was visited to confirm the presence of a nest.
A total of 210 nests were monitored under a standardized protocol (2012-2016) with temperature loggers placed inside the nest scape (2013-2016) to determine when incubation ended (see Koshkin et al. 2016b); additionally, 64 of these nests were also monitored with nest cameras. The exact date, and often time, of nest outcome was determined for $77 \%$ of the nests, using data from (in order of most accurate data) nest cameras $(n=63)$, temperature loggers $(n=30)$, nest visit on day of nest fate $(n=53)$, or satellite tracking $(n=$ 16; showing the female permanently leaving the nest). For the remaining nests (23\%; those monitored in 2012 or where the female removed the temperature logger from the nest scrape), date of outcome was taken as the midpoint between the final and penultimate monitoring visit (Mayfield 1975). Nest fate was assigned on the basis of the best available evidence: (1) outcome recorded on nest camera ( $n=63$; Supplemental Material Video S1); (2) direct observation of chicks in the scrape $(n=26)$; or (3) through field signs within and around the nest scrape (validated by nest camera recordings), supported by satellite-tracking and temperature-logger data when available ( $n=89$; for details, see Appendix). Nests were classified as either successful, if at least one egg hatched $(n=101)$; or failed (predation and other causes), if no eggs hatched. Predation $(n=58)$ involved the entire clutch being lost and could be assigned, in most cases, to desert monitor (Varanus griseus), fox (Vulpes vulpes or $V$. corsac), or hedgehog (Paraechinus hypomelas or Hemiechinus auritus), while in $25 \%$ of the cases it was not possible to determine the exact predator species. For 7 nests, although clutch loss was likely due to predation, it was not possible to attribute the exact cause of failure because of conflicting field signs. Other forms of nest failure $(n=9)$ were livestock trampling, failure to hatch long after the established Asian Houbara incubation period of 23 days, and human interference. For 32 nests, clutches were taken for artificial incubation at the Emirates Bird Breeding Center for Conservation, Uzbekistan, owing to the high risk of nest desertion after attempts to catch females at their nests to fit satellite transmitters. Lastly, for 3 nests the outcome could not be determined.

Nests known to be of captive-bred released females were excluded from analyses because the similarity of their nestsite selection to that of wild birds remains unstudied, and the present sample $(n=8)$ was considered too small to test. The origin (wild or captive-bred) of nesting females was confirmed for $61 \%$ of the studied nests through satellite tracking $(n=84)$ or nest cameras $(n=44)$, while the origin remained unconfirmed for 83 nests. However, the probability of an unconfirmed nest being from a captive-bred female was low (1.6\%; see Koshkin et al. 2016b) and, thus, any influence on the analysis will be negligible. 


\section{Measures of Vegetation Structure at Nests and Controls}

Vegetation structure was measured at all 210 nests, after the nesting event was confirmed to have finished and females with chicks were assumed to have left the area, and at 194 control sites (hereafter "controls") that were randomly generated and stratified within each of the 3 shrub assemblages to give sample sizes equivalent to the number of nests. Data were collected from nest sites toward the end of each breeding season (during May and the beginning of June), while collection of data at controls was limited to the 2013 and 2014 seasons, owing to fieldwork constraints. The shrub community is composed of long-lived, slow-growing species with a permanent woody structure that annually produces green leafy shoots that die back in winter before the next growing season. Shrub height was mostly determined by the woody parts of the crown and, to a lesser extent, by the current year's green growth. Green growth is complete by late March (J. L. Guilherme personal observation), so measurements collected at the end of the season reflected conditions during incubation. Furthermore, shrub frequency remained unchanged during the nesting season, and the structure of vegetation within each assemblage was stable between years, so we are confident that the 2013-2014 controls represent the range of structure available for the period 2012-2016.

We considered vegetation structure at 2 scales: the "nest area," a circle with a $50 \mathrm{~m}$ radius around the nest; and "nest scrape," a circle with a $2 \mathrm{~m}$ radius from the center of the scrape. For the nest area scale, the height of all shrubs (living or dead) touching each of 4 line intercepts (each 50 $\mathrm{m}$ long) radiating in cardinal directions was measured to 1 $\mathrm{cm}$ resolution. For each nest or control, pooled line intercept data provided 2 candidate structural variables: "shrub height" (mean height of all shrubs, in centimeters), considered as a direct measure of height and also as a proxy for shrub volume because it was strongly correlated with shrub diameter (Koshkin et al. 2014); and "shrub frequency" (mean number of shrubs per $200 \mathrm{~m}$ ). At the nest scrape scale, concealment was considered in terms of the proximity and height of shrubs immediately surrounding the nest. Assuming that taller (and thus wider) shrubs and those positioned closer to the nest provided greater concealment, a hypothetical "concealment index" was calculated as

$$
\text { concealment index }=\sum\left(\frac{h_{i}}{d_{i}}\right)+1
$$

where $d_{i}$ is the distance from the center of the nest scrape to the nearest shrub (to a maximum of 2 m radius) and $h_{i}$ is the height of that shrub, measured within each of 4 quadrants ( $i$; based on cardinal directions); a quadrant with no shrubs within $2 \mathrm{~m}$ contributed zero to the index.

Intercorrelation between the 3 vegetation structure variables was sufficiently low (examined separately for nests and controls in each shrub assemblage, all Pearson's $\left.r^{2} \leq 0.40\right)$ that these could be treated as independent predictor variables in analyses (following Freckleton 2002).

\section{Statistical Analysis}

Sample sizes used for all analyses within each shrub assemblage were as follows: Astragalus, 91 nests and 97 controls; S. arbuscula, 96 nests and 57 controls; and S. rigida, 23 nests and 40 controls. One nest was considered an outlier and excluded from the analyses, because it was, exceptionally, found directly under a white saxaul in the $S$. arbuscula shrub assemblage (concealment index $>3$ times higher than that of the next-ranked nest).

Structure of available and used vegetation. We examined whether the structure of the vegetation available to females differed between the 3 shrub assemblages (using measures from control locations). Group means were compared using general linear models (GLMs) with normal error distribution, applying Bonferroni corrections for multiple comparisons; to satisfy conditions of homoscedasticity, shrub height and concealment index were respectively square-root- and logtransformed, after first confirming that variances were similar among assemblages (pairwise 2-tailed Levene's tests were all nonsignificant, pooling across the 2 sampling years; Appendix Table 1).

Next we examined whether females selected similar vegetation structure across different shrub assemblages by comparing measures taken at nests. We used normal-error generalized linear mixed-effect models (GLMMs) to accommodate a random (intercept) effect of "female identity" (to account for several nests of some satellitetagged females), again testing differences between group means with Bonferroni corrections for multiple comparisons, using square-root shrub height and log-concealment index, and after first testing for similarity of variances of each variable between shrub assemblages (pairwise 2-tailed Levene's tests were all nonsignificant for shrub height and concealment index, but relationships of shrub frequency variances were mixed among shrub assemblages when pooling data from the 5 breeding seasons; Appendix Table $1 C)$.

Nest-site selection. Separately within each shrub assemblage, we tested the a priori hypothesis that vegetation structure measures would have lower variance at nests than at controls as a result of female selection, using a one-tailed Levene's test. We then assessed the relative importance of vegetation structure measures in predicting nesting probability using binomial models of nests vs. controls in a used/available design, both 
separately for the nest area and nest scrape scales, and then combining across scales. In each case, candidate variables were assessed by multimodel inference (MMI; Burnham and Anderson 2002) of GLMMs with a binomial error distribution, coding nests as 1 and controls as 0 , including female identity as a random effect, and pooling data across years.

At the nest area scale, candidate measures of shrub height, its quadratic term shrub height ${ }^{2}$ (because we expected, a priori, that site selection would be within a range of shrub heights), and shrub frequency were assessed by MMI. We examined each shrub assemblage (Astragalus, $S$. arbuscula, and $S$. rigida) separately, because pairwise contrasts of means at controls (see above) showed that mean shrub height and mean shrub frequency of available vegetation differed between shrub assemblages (see below; Figure 1A, 1B). At the nest scrape scale, candidate models of concealment index and its quadratic term concealment index $^{2}$ (because we expected, a priori, that nest scrape selection would be within a restricted range of concealment) were also examined by MMI, but pooling data across shrub assemblages, because concealment index values at both controls and nests showed similar variance (all pairwise Levene's tests nonsignificant; Appendix Table 1) and mean across the 3 shrub assemblages (see below; Figure $1 C$ ).

To investigate the relative importance of vegetation structure to nest-site selection at each of these 2 scales (nest area and scrape), and whether these interact to affect nest occurrence probability, we considered all candidate variables (nest area: shrub height, shrub height ${ }^{2}$, and shrub frequency; nest scrape: concealment index and concealment index ${ }^{2}$ ), combining data from the 3 shrub assemblages in MMI. Initial exploratory modeling showed no support for including either additive or interaction effects of "shrub assemblage," because its inclusion resulted in an increase of Akaike's Information Criterion corrected for small samples $\left(\mathrm{AIC}_{\mathrm{c}}\right)$.

For MMI, model-averaged parameter estimates and relative variable importance (RVI; varying $0-1$ ) of each variable were calculated from each set of candidate models; quadratic terms were considered conditional on the presence of the original input variables, so we removed those models including the quadratic term of a variable but not its linear term. Following Whittingham et al. (2005), a randomly generated variable $($ mean $=1, \mathrm{SD}=1$ ) was incorporated in the candidate variable set to estimate the RVI that could occur by chance for predictors unrelated to the dependent variable, and the MMI analysis was repeated 1,000 times each with a newly generated random variable. Subsequently, candidate variables were considered strongly supported if their RVI was above the 95\% interval of the RVI distribution of the random null variate and if the 95\% confidence limit of the model-averaged parameter did not span zero (following Boughey et al. 2011).

Nest survival. Finally, we related the daily probability of a nest escaping predation (daily survival rate [DSR]) to vegetation structure at nest area and nest scrape scales. Of the 210 nests monitored, 186 were suitable for inclusion in a DSR analysis. All nests that escaped predation were coded 0 ; these include nests that successfully hatched $(n=$ 91), nests that survived until the clutch was collected for artificial incubation during attempts to catch females for satellite tagging ( $n=32$; recorded as successful up to that date), and those unsuccessful because of human interference $(n=2)$, livestock trampling $(n=4)$, or failure to hatch after prolonged incubation periods $(n=3$; listed as successful up to the predicted hatching date). Nests that failed as a result of predation were coded 1 and include predation events by desert monitor $(n=29)$, hedgehog $(n=$ 2 ), fox $(n=6)$, and unknown predators (most likely fox; $n=$ 11); nests that were most likely depredated but for which conflicting evidence did not allow us to distinguish predation from other causes of failure with certainty $(n=$ 6) were also coded 1 in order to prevent possible bias from excluding these failed nests. Analyses were repeated excluding these 6 nests, and no results differed significantly or qualitatively. Twenty-four nests were unsuitable for DSR analysis, comprising 18 found on the day of hatching or predation (i.e. with zero exposure days), 3 where females were flushed by our vehicle (considered to have been compromised because all were depredated within one day), and 3 with unknown outcome. We constructed models in RMARK (8.2; White and Burnham 1999), such that DSR can vary both with season and across incubation (Dinsmore et al. 2002). Preliminary analysis confirmed (as previously shown by Koshkin et al. 2016b) that DSR initially decreases during the breeding season and then increases again toward the end. Therefore, both "date" (day in season) and its quadratic term date ${ }^{2}$ were forced into all nest survival models. Candidate models of nest survival examined effects of shrub height, concealment index, shrub assemblage, and year (because nest predation was expected, a priori, to vary among years, depending on the abundance of predators and also their alternative prey), while controlling for date and date ${ }^{2}$. Shrub frequency was excluded because it was not supported in all previous analyses. Exploratory modeling showed no support for additional quadratic terms for shrub height and concealment index, or for the interaction of shrub assemblage with these variables, because their inclusion individually and together led to increased $\mathrm{AIC}_{\mathrm{c}}$; therefore, they were excluded from further analysis. MMI and RVI were applied following the methods detailed above. A random effect could not be included in the RMARK nest survival model, so we tested the effect of female identity using a separate binomial GLMM of nest 

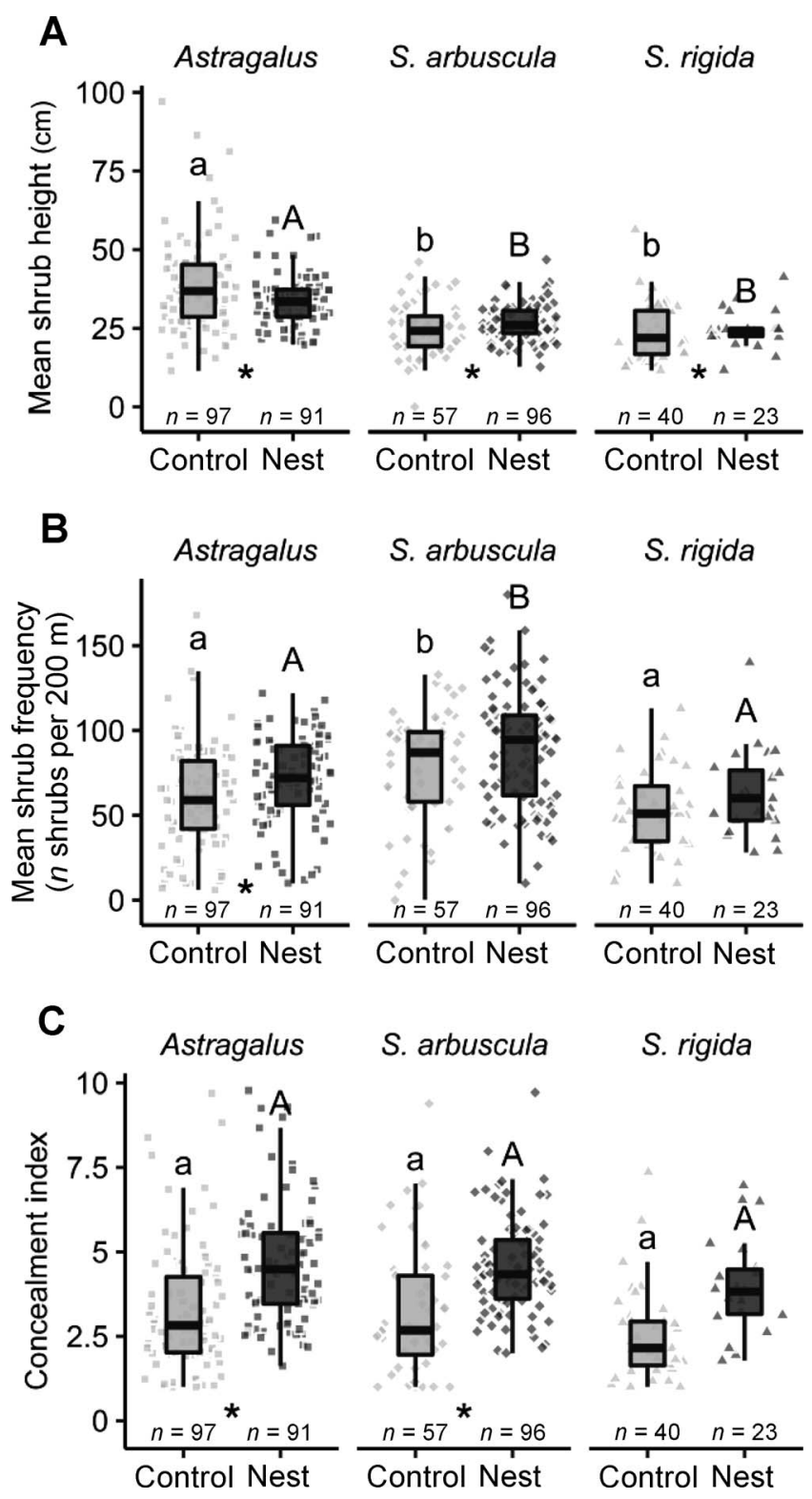

FIGURE 1. Vegetation structure at Asian Houbara nest sites (dark gray symbols) and control points (light gray symbols) at 2 scales: $(\mathbf{A}, \mathbf{B})$ the nest area (50 m radius) and (C) the nest scrape $(2 \mathrm{~m}$ radius), within each of 3 shrub assemblages (Astragalus, Salsola arbuscula, and S. rigida): (A) mean shrub height, (B) mean shrub frequency, and $(\mathbf{C})$ concealment index (values $>10$ excluded to facilitate visualization). Dark lines represent the median, boxes the interquartile range, and symbols the data points (horizontal jitter added for clarity). Asterisk denotes significant one-tailed Levene's test $(P<0.05)$ of the a priori hypothesis, within each shrub assemblage, that variance is less across nests than across controls (test results in Appendix Table 1A). Superscript letters show homogeneous subsets of means (from pairwise contrasts with Bonferroni correction, $P<0.05$ ) of controls (lowercase) and nests (uppercase) across shrub assemblages (using generalized linear models and generalized mixed-effect models, respectively, to accommodate female identity; test results in Appendix Table 2). outcome, considering exposure days as the number of binomial trials, including lay date + lay date ${ }^{2}$ (analogous to, but not as detailed as, the RMARK date method), shrub height, and concealment index; female identity as random effect showed zero variance, warranting its exclusion from further survival analysis.

All statistical analyses and calculations were performed in $\mathrm{R}$ 3.3.3 ( $\mathrm{R}$ Development Core Team 2016), using package lme4 1.1-12 (Bates et al. 2014) to build the models, package MuMIn 1.15.1 (Bartón 2013) for MMI analyses, and package RMark 2.2.2 (Laake 2013) for the nest survival analysis.

\section{RESULTS}

Structure of available and used vegetation. At the nest area (50 m radius) scale, the shrub vegetation available to nesting females (measured at controls) was structurally diverse and differed between the 3 shrub assemblages: mean shrub height was taller in Astragalus than in $S$. arbuscula and $S$. rigida, which did not differ, while shrub frequency was greater in $S$. arbuscula than in either Astragalus or S. rigida (Figure 1A, 1B; Appendix Table 2A). Overall, Astragalus was characterized by dispersed taller shrubs, S. arbuscula by lower but more frequent shrubs, and $S$. rigida by dispersed low shrubs (Figure 1A, 1B; Appendix Figure 5). At the nest scrape scale, however, variance and mean concealment index measured at controls did not differ between shrub assemblages (Figure 1C; Appendix Table 2A).

Vegetation structure around nests also differed among shrub assemblages, in directions that reflected differences in the available vegetation. At the nest area scale, mean shrub height was taller in Astragalus than in either $S$. arbuscula or S. rigida, which did not differ; and shrub frequency was greater in $S$. arbuscula than in either Astragalus or S. rigida, which did not differ (Figure 1A, 1B; Appendix Table 2B and Appendix Figure 5). As in controls, at the nest scrape scale nests had similar concealment indices between assemblages (Figure 1C; Appendix Table 2B and Appendix Figure 5).

Nest-site selection. Comparison of vegetation structural variables between nests and controls suggests that females actively selected their nest sites. At the nest area scale, nest locations showed less variance in shrub height than controls in each of the 3 shrub assemblages (onetailed Levene's tests; Figure 1A; Appendix Table 1A); for shrub frequency, the variance at nests was less than at controls in Astragalus, while no differences were apparent for either of the other 2 shrub assemblages (Figure 1B; Appendix Table 1A). At the nest scrape scale, nests had less variance in concealment index than at controls in both Astragalus and $S$. arbuscula, but this contrast was marginally nonsignificant in S. rigida (Figure 1C; Appendix 
Table 1A). This inequality of variances between nests and controls precluded using GLM (with normal error) to compare means of vegetation structure between nest and control locations, but nest-site selection in relation to controls could be assessed by binomial models.

At the nest area scale, the probability of nest occurrence was nonlinearly related to shrub height, with a quadratic relationship strongly supported (selection of the quadratic term was robust despite being underrepresented in the MMI) for both Astragalus and S. arbuscula, while there was no support for shrub frequency (parameter estimates shown in Figure 2B, 2D). In S. rigida the null model had the best $\mathrm{AIC}_{\mathrm{c}}$ and no candidate variables received support (all RVIs within the 95\% null interval and confidence limits spanning zero; parameter estimates shown in Figure 2F). The shrub height (at the nest area scale) at which probability of nest occurrence was predicted to be maximum was remarkably consistent between shrub assemblages: $31.5 \mathrm{~cm}$ in Astragalus, $29.5 \mathrm{~cm}$ in $S$. arbuscula, and $29.6 \mathrm{~cm}$ in S. rigida (Figure 2A, 2C, 2E).

At the nest scrape scale, nest occurrence was related to the concealment index, with a quadratic relationship receiving strong support (despite concealment index ${ }^{2}$ being underrepresented in the MMI), with the best model including both variables (parameter estimates in Figure $2 \mathrm{H}$ ). Highest relative probabilities of nest occurrence were at an index value of 16.9 (Figure 2G), above the upper 95\% of values measured at controls, indicating selection for highly concealed nest scrapes.

In MMI of candidate cross-scale models, combining nest area and nest scrape scales and pooling across shrub assemblages, the effects of shrub height and shrub height ${ }^{2}$, and of concealment index and concealment index ${ }^{2}$, were all strongly supported, with no support for any effect of shrub frequency (Figure 3C). The quadratic effect and selection of intermediate shrub height in the surrounding area (Figure 3A) suggest that female Asian Houbara choose nest sites both for clear view and for protection from view, as well as selecting highly concealed nest scrapes (Figure 3B).

Nest survival. Mean nest survival, denoted here as the probability of escaping predation, was $57.5 \%(\mathrm{SE}=4.33 \%)$ across the 5 breeding seasons. MMI showed no support for a difference of DSR between years or shrub assemblages (Figure 4C). A positive relationship showing that taller shrubs in the nest area reduce the probability of predation was strongly supported. When taking date into account, taller shrubs in the nest area consistently provided a nest survival advantage (with no overlap in confidence interval of predicted nest survival probability for the upper 95\% and lower $5 \%$ quantiles of shrub height) throughout almost the entire season. However, the differences in predation probability between the short and tall shrub heights became more pronounced in the middle of the breeding season, when predators were increasingly active (Figure 4A). Surprisingly, however, the level of scrape concealment (as given by the concealment index) did not influence whether nests avoided predation (Figure 4B). Finally, from all nests monitored, there were no recorded events of females being depredated at the nest.

\section{DISCUSSION}

Vegetation structure, especially height of shrubs and level of concealment, plays an important role in nest-site choice by female Asian Houbara. At the nest area scale $(50 \mathrm{~m}$ radius around the nest), females selected a narrower range of intermediate shrub heights from the available vegetation structure. Although the mean shrub height around nests differed slightly, the peak probability of nest-site occurrence from MMI was consistent (range: 29.5-31.5 cm) across all 3 shrub assemblages. Shrub height had a positive but linear association with nest survival suggesting that, within the observed range, incrementally greater shrub height continued to increase concealment from predators. Furthermore, it is conceivable that nests placed in areas with taller shrubs than the observed range may have received even greater survival benefit. However, the probability of nest placement peaked at intermediate heights in relation to the available distribution, even though such nests carry a cost of increased nest predation risk when taller shrubs are available. We suggest that nesting in even taller shrub heights would trade off nest concealment against vigilance capability. Given that there were no recorded predations of females from $>200$ nesting attempts, it appears that approaching an incubating female without being detected is extremely hard. At the nest scrape scale (2 $\mathrm{m}$ radius), females exhibited a strong selection for more concealed sites, indicating an optimum arrangement of shrubs around the nest scrape based on their height (i.e. taller shrubs can be farther from the scrape and shorter shrubs need to be closer). However, contrary to our prediction, selection for more concealed nest scrapes failed to improve nest survival.

\section{The Role of Vegetation Structure}

The striking similarity found in nest sites across shrub assemblages indicates consistent female selection for nest placement that may be interpreted as reflecting optimal conditions for nesting across the southern Kyzylkum, and illustrates how carefully balanced the process of nest-site choice is. Previous studies addressing fine-scale habitat selection of nesting houbara species (Chlamydotis spp.) have highlighted the importance of vegetation structure for nest-site selection, generally involving low, sparse vegetation (Yang et al. 2003, Hingrat et al. 2008, Aghanajafizadeh et al. 2012). However, drawing comparisons between these studies is problematic because they 


\section{A Astragalus}

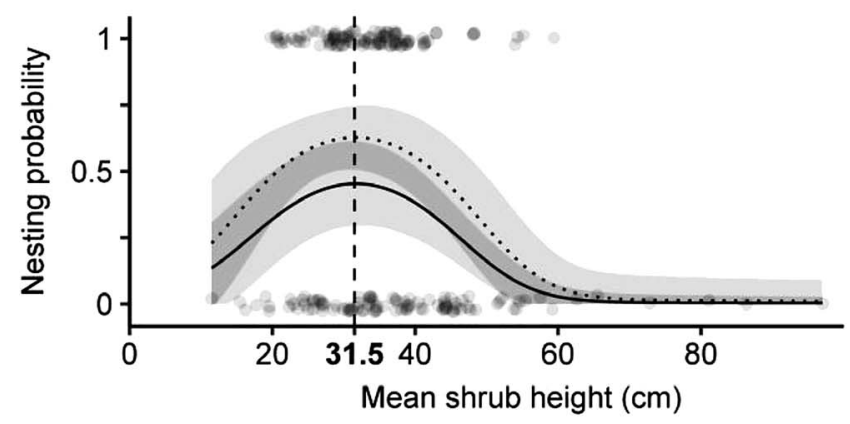

C Salsola arbuscula

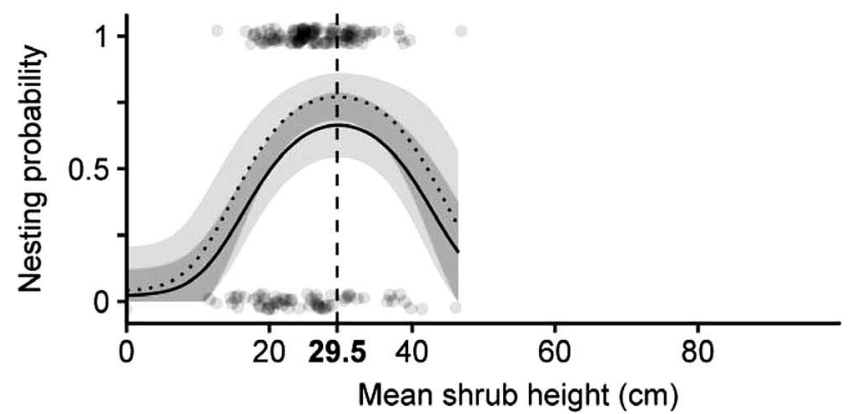

E Salsola rigida

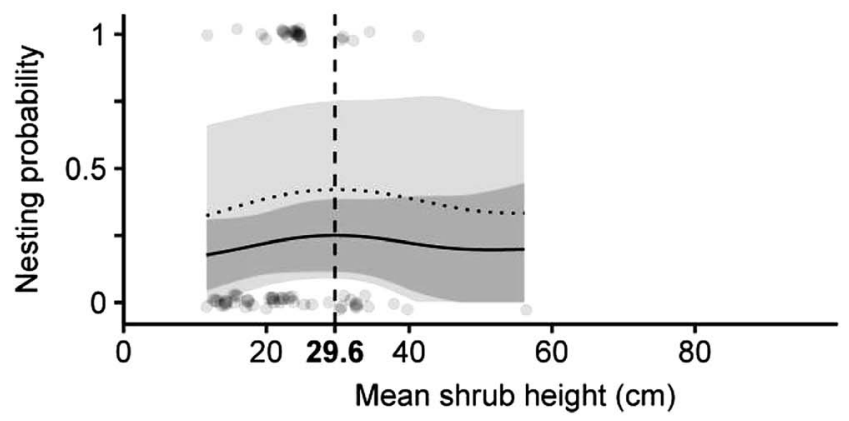

G All shrub assemblages

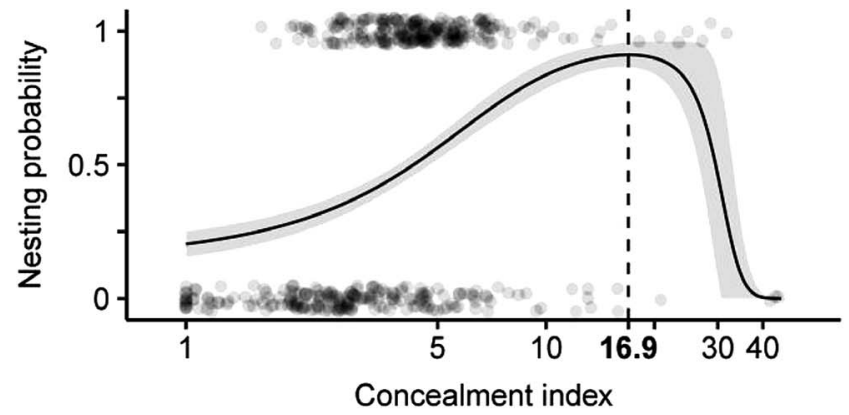

B

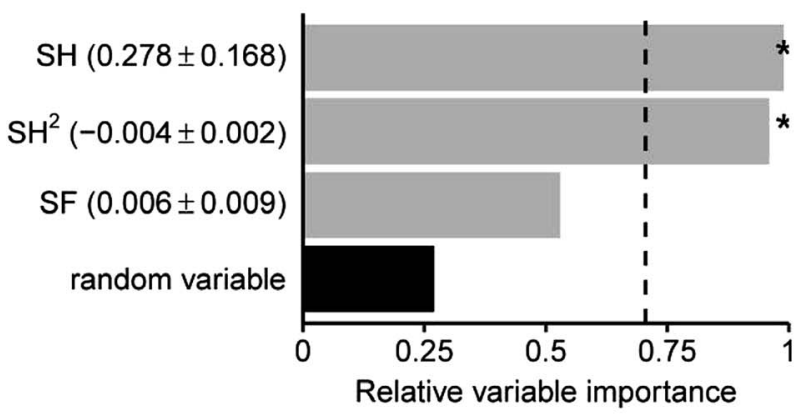

D

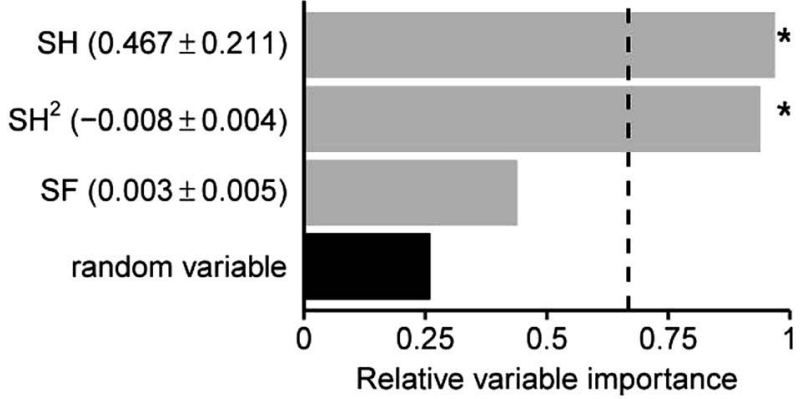

$\mathbf{F}$

SH $(0.091 \pm 0.240)$

SF $(0.007 \pm 0.016)$

$\mathrm{SH}^{2}(-0.002 \pm 0.004)$

random variable

\section{Salsola rigida}

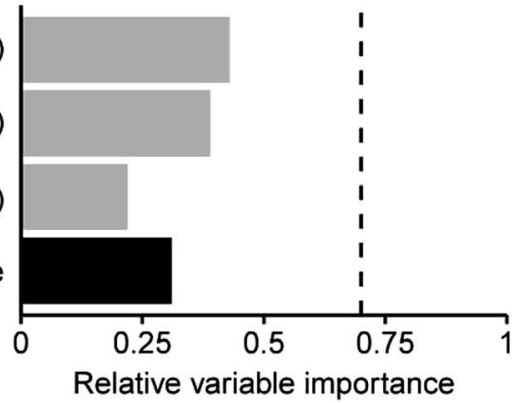

H

All shrub assemblages

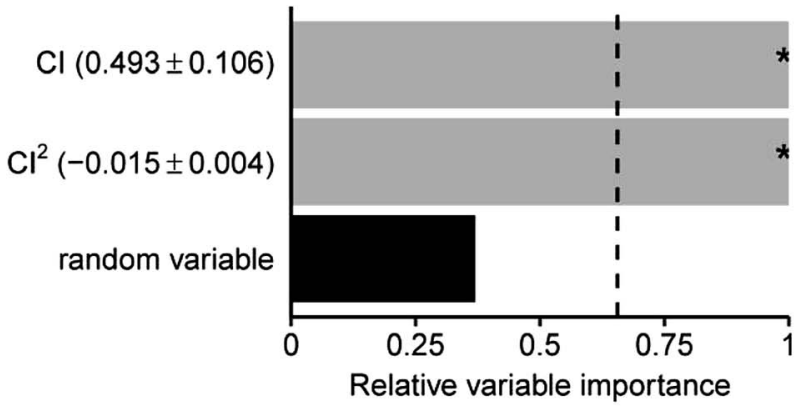

FIGURE 2. (Left column) Nest-site selection by female Asian Houbara: modeled probability of nesting in (A) Astragalus, (C) Salsola arbuscula, and (E) S. rigida at the nest area (50 m radius) scale in relation to mean shrub height ( $95 \%$ confidence interval shaded), showing additive effects of mean shrub frequency (as dotted and solid lines, representing the maximum and minimum respectively); and $(\mathbf{G})$ in all shrub assemblages at the nest scrape ( $2 \mathrm{~m}$ radius) scale in relation to concealment index. Vertical dashed line and the bold value on the $x$-axis show mean vegetation structure (mean shrub height or concealment index) with the highest nesting probability; on the $y$-axis, 1 represents nests and 0 controls, with observations shown as jitter. (Right column) Relative variable 
each used different methodologies to quantify habitat. Importantly, from the aspect of study design, we demonstrated that unless nest-site choice is analyzed separately across a range of shrub assemblages, important cues could be missed if sampling is limited to homogeneous habitats. Particularly, the probability of occurrence tests in the Astragalus and S. arbuscula habitats showed that shrub height was important, because these habitats contain taller and shorter vegetation, respectively, than that selected by Asian Houbara. However, in the third habitat, S. rigida, prevailing vegetation height already matches the optimum; therefore, if analyzed in isolation, the importance of shrub height might be overlooked (although the variance tests of shrub height showed that selection was still occurring in this habitat).

In addition to vegetation structure, factors that have been suggested to affect houbara nest-site suitability or nest survival include the abundance of arthropods (Hingrat et al. 2007, Aghanajafizadeh et al. 2012), presence and abundance of key predators (Yang et al. 2003), and density of edible or succulent plants, specifically Salsola spp. (Alekseev 1985, Yang et al. 2003). However, in the southern Kyzylkum, female houbara start nesting shortly after their return from the wintering grounds (earliest laying dates March 14-24 and median dates April 1-8 in 2012-2015; Koshkin et al. 2016b), when temperatures are still low, shrubs and invertebrates dormant (Koshkin et al. 2016b), and desert monitors still hibernating (Tsellarius et al. 1995). It is possible that vegetation structure offers an early proxy by which females can predict food availability during incubation, or for their brood, but given the subtle difference of selected nest sites from prevailing vegetation, combined with nesting across a range of shrub assemblages, this does not seem a likely mechanism.

\section{Visual Security, Concealment, and Nest Survival}

Selection for particular nest-site features can affect the survival of both clutch and incubating bird (Martin 1998, Clark and Shutler 1999), so females should nest in places that offer protection for both their eggs and themselves. Selection of nest areas peaked at intermediate shrub heights similar to the head height of an incubating female houbara (measured from taxidermist-mounted decoys in non-alert position as $23-27 \mathrm{~cm}, n=4$; but $5-10 \mathrm{~cm}$ taller when the neck is extended in upright alert posture), which suggests that females favor less exposed (more concealing) places that still provide good visibility, possibly to improve early detection of approaching danger. This way females can vacate the nest, slipping away rapidly but surreptitiously, before a potential predator arrives at the site (as frequently seen from nest cameras; Supplemental Material Video S2), simultaneously ensuring their own safety (Yang et al. 2003, Miller et al. 2007, Magaña et al. 2010) and improving the daily survival of the nests (e.g., Lloyd 2004). Furthermore, nests placed in areas with taller shrubs had greater nest survival, indicating that taller shrubs did not compromise visual security, at least within the range of shrub heights at which nests were placed.

We also found strong selection for concealed nest scrapes, and previous studies of Chlamydotis spp. have also reported selection for more screened sites, with African Houbara (C. undulata) laying their eggs closer to a shrub than random sites (Hingrat et al. 2008) and anecdotal evidence from Pakistan similarly indicating that Asian Houbara frequently place nests near a taller shrub (Mian 1998). Despite this clear female preference, placing the scrape in a well-concealed position had no effect on nest survival. Similar results, with preference for concealment that did not increase nest success, have been reported for Greater Sage-Grouse (Centrocercus urophasianus) in Wyoming, USA (Dinkins et al. 2016), and Woodlark (Lullula arborea) in the UK (Mallord et al. 2007). It is possible that all nests may have met a minimum requirement for screening an incubating female, such that no benefit of further concealment was found. Nevertheless, the consistent selection of a concealing position may have other benefits (e.g., shrub shading and wind protection helping to regulate temperature and water loss of either the clutch [Hingrat et al. 2008, Tieleman et al. 2008] or the incubating female, or reducing stress to the incubating bird).

\section{Conservation Implications}

Asian Houbara populations are under pressure from unregulated hunting and poaching and from increasing encroachment in the deserts due to expanding infrastructure, mining, gas extraction, and extraction of fuelwoods (Combreau et al. 2001, Allinson 2014). Clearly, their first form of nest defense is undetectability in the vast deserts with generally low densities of predators. Although the studied population currently seems to have a healthy nest survival rate, the fate of individual nests is largely stochastic and likely directly related to predator density (Koshkin et al. 2016b). Asian Houbara appear to have quite specific criteria regarding the structure of nest sites, which also influences the rate of nest predation. Any activities in

importance (RVI) of candidate variables and model-averaged coefficients \pm SE (in parentheses) at the nest area scale for (B) Astragalus, (D) Salsola arbuscula, (F) S. rigida, and (H) all shrub assemblages. Black bars are the median RVI of a random null variable (generated across 1,000 multimodel inference iterations), with the dashed line representing its upper $95 \%$ null limit; asterisk denotes strongly supported predictors. Abbreviations: $\mathrm{SH}=$ mean shrub height, $\mathrm{SF}=$ mean shrub frequency, $\mathrm{Cl}=\mathrm{concealment}$ index. 

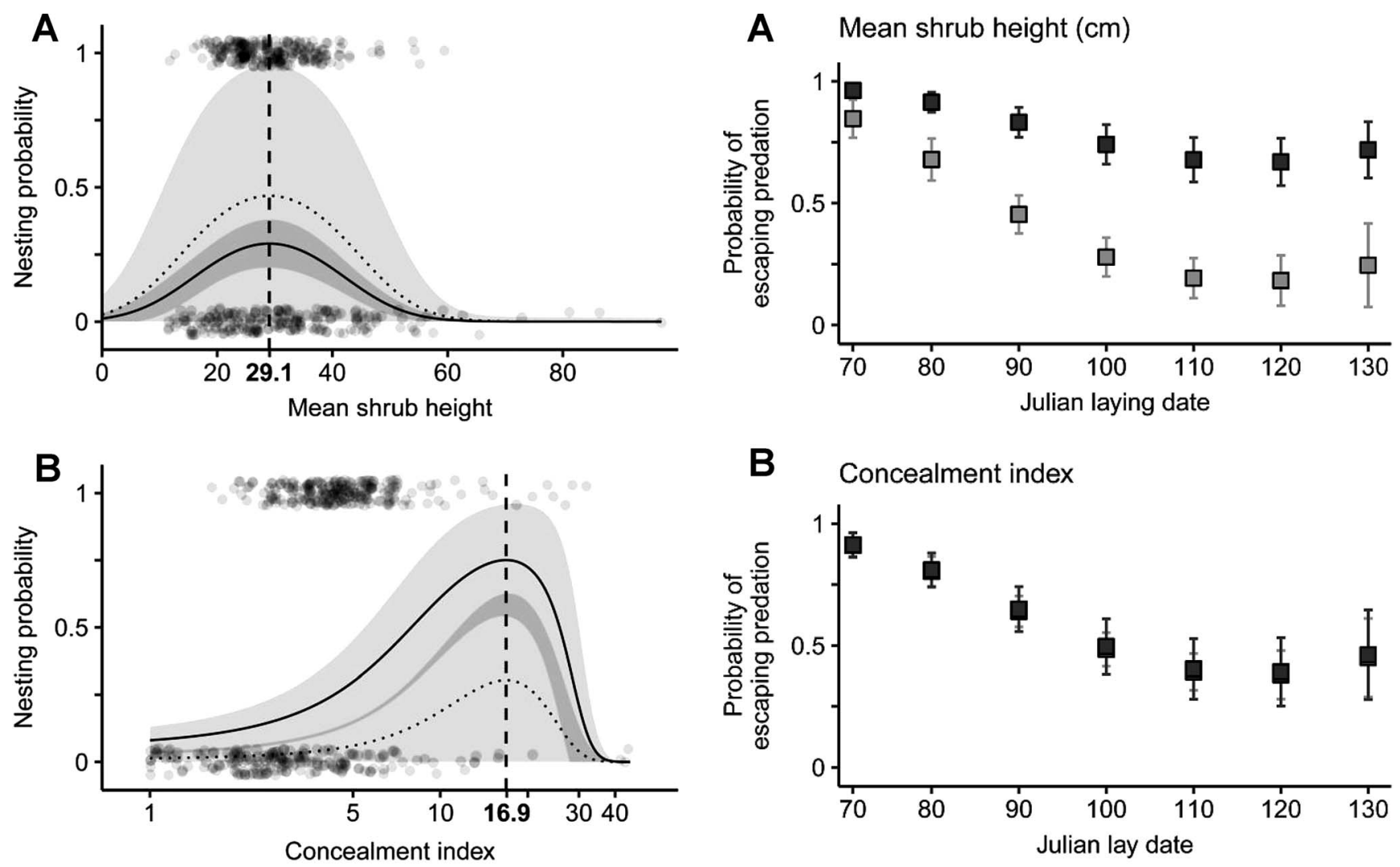

B Concealment index
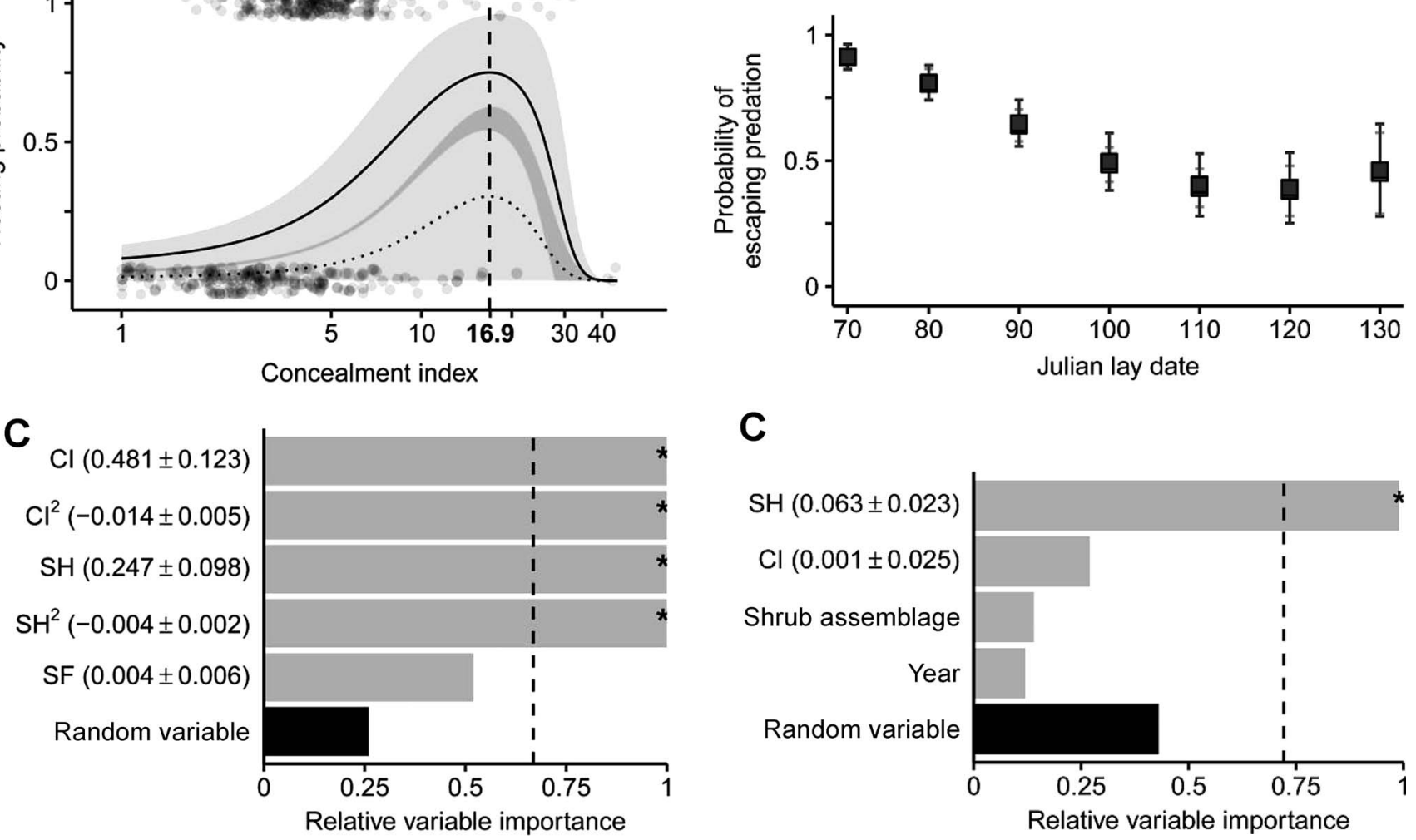

FIGURE 3. (A, B) Nest-site selection by female Asian Houbara; modeled probability of nesting in relation to vegetation structure at multiple scales (merged across shrub assemblages) considering (A) mean shrub height, showing additive effects of mean shrub frequency and concealment index; and (B) concealment index, showing additive effects of mean shrub frequency and mean shrub height. Dotted and solid lines represent the maximum and minimum, respectively, of the variable; shaded areas represent 95\% confidence intervals; vertical dashed line and the bold value on the $x$-axis show mean vegetation structure (mean shrub height or concealment index) with the highest nesting probability; on the $y$-axis, 1 represents nests and 0 controls, with observations shown as jitter. (C) Relative variable importance (RVI) of candidate variables with model-averaged coefficients $\pm \mathrm{SE}$; black bars are the median RVI of a random null variable (generated across 1,000 multimodel inference iterations), with the dashed line representing its upper 95\% null limit; asterisk denotes strongly supported predictors. Abbreviations: $\mathrm{SH}=$ mean shrub height, $\mathrm{SF}=$ mean shrub frequency, $\mathrm{Cl}=$ concealment index.

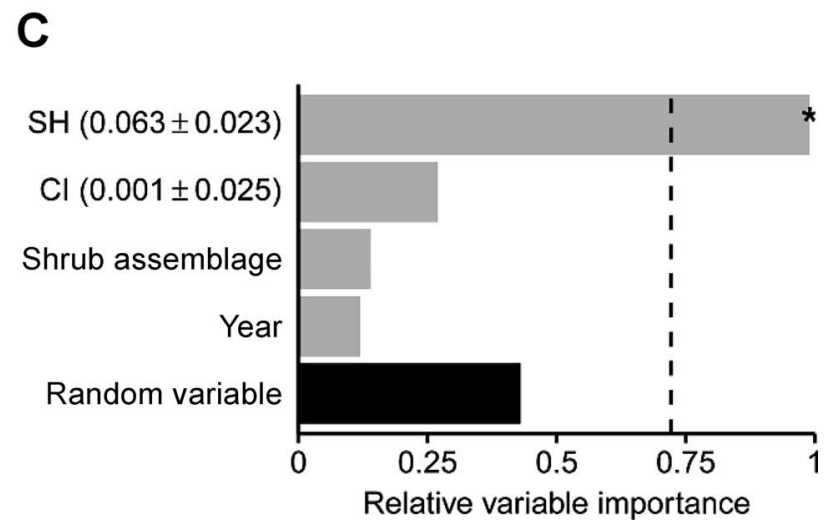

FIGURE 4. Estimated probability of Asian Houbara nests surviving predation in relation to (A) mean shrub height, showing additive effects of concealment index; and (B) concealment index, showing additive effects of mean shrub height. Dark gray and light gray symbols represent, respectively, the upper $95 \%$ and lower $5 \%$ quantiles of mean shrub height $(42.7 \mathrm{~cm}$ and $19.4 \mathrm{~cm}$ ) and of concealment index (11.0 and 2.2). (C) Relative variable importance of candidate variables with model-averaged coefficients ( $\pm \mathrm{SE}$ ), except for shrub assemblage (3 categories: S. arbuscula [-0.0003 \pm 0.12$]$, S. rigida [-0.021 \pm 0.18$]$, referenced to Astragalus), and year (5 categories: $2013[0.021 \pm 0.18], 2014[0.037 \pm 0.20], 2015$ [-0.005 \pm 0.16$], 2016$ [-0.037 \pm 0.20$]$, referenced to 2012); black bars are the median RVI of a random null variable (generated across 1,000 multimodel inference iterations), with the dashed line representing its upper $95 \%$ null limit; asterisk denotes strongly supported predictors. Abbreviations: $\mathrm{SH}=$ mean shrub height, $\mathrm{Cl}=$ concealment index. 
the landscape that lead to changes in vegetation structure and/or increases in predators are likely to affect the productivity of the populations in 3 ways, by (1) reducing the availability of suitable nesting habitat; (2) reducing nest success by modifying shrub structure through the denudation of natural vegetation, thus reducing concealment; and (3) increasing predator densities associated with human encroachment. These changes could additively reduce nesting success and, hence, the viability of wild populations.

\section{ACKNOWLEDGMENTS}

We warmly thank M. Koshkin, E. Khaitov, E. Grayshon, D. Hodkinson, L. M. Jane, J. Mateos-Herrero, C. Packman, D. Showler, and A. Taylor for their contributions to data collection and enthusiasm during fieldwork. A. Butnik and T. Rajabov, Academy of Sciences of Uzbekistan, helped validate our identification of desert shrubs. J.L.G. thanks J. Fischer for hosting him in his group at Leuphana University during the preparation of the manuscript.

Funding statement: This study was funded by the Ahmed bin Zayed Charitable Foundation. The Emirates Bird Breeding Center for Conservation provided invaluable collaboration and logistical support during fieldwork. None of our funders had any influence on the content of the submitted or published manuscript. None of our funders required approval of the final manuscript to be published.

Ethics statement: This study was authorized by the State Committee for Nature Conservation of the Republic of Uzbekistan.

Author contributions: P.M.D., R.J.B, N.J.C., and J.L.G. conceived the study, formulated the questions, and cowrote the paper. P.M.D., R.J.B., and J.L.G. designed field protocols. R.J.B. and J.L.G. supervised data collection and analyzed the data. J.L.G. led the preparation of the manuscript.

\section{LITERATURE CITED}

Aghanajafizadeh, S., M. R. Hemami, and F. Heydari (2012). Nestsite selection by the Asian Houbara Bustard, Chlamydotis macqueenii, in the steppe of Harat, Iran: (Aves: Otidae). Zoology in the Middle East 57:11-18.

Alekseev, A. F. (1985). The houbara bustard in the north-west Kyzylkum (U.S.S.R.). Bustard Studies 3:87-91.

Allinson, T. (2014). Review of the global conservation status of the Asian Houbara bustard Chlamydotis macqueenii. Report to the Convention on Migratory Species Office-Abu Dhabi. Cambridge, UK: BirdLife International.

Bartón, K. (2013). Package MuMln R package version 1.15.1. http://cran.r-project.org/web/packages/MuMln/index.html

Bates, D., M. Mächler, B. Bolker, and S. Walker (2014). Fitting linear mixed-effects models using Ime4. Journal of Statistical Software 67:1-48.

BirdLife International (2016). Species factsheet: Chlamydotis macqueenii. http://www.birdlife.org
Borgmann, K. L., and C. J. Conway (2015). The nest-concealment hypothesis: New insights from a comparative analysis. The Wilson Journal of Ornithology 127:646-660.

Boughey, K. L., I. R. Lake, K. A. Haysom, and P. M. Dolman (2011). Effects of landscape-scale broadleaved woodland configuration and extent on roost location for six bat species across the UK. Biological Conservation 144:2300-2310.

Burnham, K. P., and D. R. Anderson (2002). Model Selection and Multimodel Inference: A Practical Information-Theoretic Approach, second edition. Springer, New York, NY, USA.

Burnside, R. J., N. J. Collar, and P. M. Dolman (2017). Comparative migration strategies of wild and captive-bred Asian Houbara Chlamydotis macqueenii. Ibis 159:374-389.

Camp, M. J., J. L. Rachlow, B. A. Woods, T. R. Johnson, and L. A. Shipley (2013). Examining functional components of cover: The relationship between concealment and visibility in shrub-steppe habitat. Ecosphere 4:1-14.

Chalfoun, A. D., and K. A. Schmidt (2012). Adaptive breedinghabitat selection: Is it for the birds? The Auk 129:589-599.

Clark, R. G., and D. Shutler (1999). Avian habitat selection: Pattern from process in nest-site use by ducks? Ecology 80 : 272-287.

Combreau, O., F. Launay, and M. Lawrence (2001). An assessment of annual mortality rates in adult-sized migrant houbara bustards (Chlamydotis undulata macqueenii). Animal Conservation 4:133-141.

Conover, M. R., J. S. Borgo, R. E. Dritz, J. B. Dinkins, and D. K. Dahlgren (2010). Greater Sage-Grouse select nest sites to avoid visual predators but not olfactory predators. The Condor 112:331-336.

Dinkins, J. B., K. T. Smith, J. L. Beck, C. P. Kirol, A. C. Pratt, and M. R. Conover (2016). Microhabitat conditions in Wyoming's sage-grouse core areas: Effects on nest site selection and success. PLOS One 11:e0150798.

Dinsmore, S. J., G. C. White, and F. L. Knopf (2002). Advanced techniques for modeling avian nest survival. Ecology 83: 3476-3488.

Freckleton, R. P. (2002). On the misuse of residuals in ecology: Regression of residuals vs. multiple regression. Journal of Animal Ecology 71:542-545.

Götmark, F., D. Blomqvist, O. C. Johansson, and J. Bergkvist (1995). Nest site selection: A trade-off between concealment and view of the surroundings? Journal of Avian Biology 26: 305-312.

Hingrat, Y., M. Saint Jalme, T. Chalah, N. Orhant, and F. Lacroix (2008). Environmental and social constraints on breeding site selection. Does the exploded-lek and hotspot model apply to the houbara bustard Chlamydotis undulata undulata? Journal of Avian Biology 39:393-404.

Hingrat, Y., F. Ysnel, M. Saint Jalme, J. Le Cuziat, P.-M. Béranger, and F. Lacroix (2007). Assessing habitat and resource availability for an endangered desert bird species in eastern Morocco: The houbara bustard. Biodiversity and Conservation 16:597-620.

Ibáñez-Álamo, J. D., R. D. Magrath, J. C. Oteyza, A. D. Chalfoun, T. M. Haff, K. A. Schmidt, R. L. Thomson, and T. E. Martin (2015). Nest predation research: Recent findings and future perspectives. Journal of Ornithology 156 (Supplement 1):247-262.

Johnson, M. D. (2007). Measuring habitat quality: A review. The Condor 109:489-504. 
Koshkin, M. A., R. J. Burnside, N. J. Collar, J. L. Guilherme, D. A. Showler, and P. M. Dolman (2016a). Effects of habitat and land use on breeding season density of male Asian Houbara Chlamydotis macqueenii. Journal of Ornithology 157:811-823.

Koshkin, M. A., R. J. Burnside, C. E. Packman, N. J. Collar, and P. M. Dolman (2016b). Effects of habitat and livestock on nest productivity of the Asian Houbara Chlamydotis macqueenii in Bukhara Province, Uzbekistan. European Journal of Wildlife Research 62:447-459.

Koshkin, M. A., N. J. Collar, and P. M. Dolman (2014). Do sheep affect distribution and habitat of Asian Houbara Chlamydotis macqueenii? Journal of Arid Environments 103:53-62.

Laake, J. L. (2013). RMark: An R interface for analysis of capturerecapture data with MARK. U.S. Department of Commerce, National Oceanic and Atmospheric Administration, National Marine Fisheries Service, Alaska Fisheries Science Center.

Lack, D. L. (1968). Ecological Adaptations for Breeding in Birds. Methuen, London, UK.

Lloyd, P. (2004). Variation in nest predation among arid-zone birds. Ostrich 75:228-235.

Magaña, M., J. C. Alonso, C. A. Martín, L. M. Bautista, and B. Martín (2010). Nest-site selection by Great Bustards Otis tarda suggests a trade-off between concealment and visibility. Ibis 152:77-89.

Mallord, J. W., P. M. Dolman, A. F. Brown, and W. J. Sutherland (2007). Nest site characteristics of Woodlarks Lullula arborea breeding on heathlands in southern England: Are there consequences for nest survival and productivity? Bird Study 54:307-314.

Martin, T. E. (1993). Nest predation among vegetation layers and habitat types: Revising the dogmas. The American Naturalist 141:897-913.

Martin, T. E. (1998). Are microhabitat preferences of coexisting species under selection and adaptive? Ecology 79:656-670.

Mayfield, H. F. (1975). Suggestions for calculating nest success. The Wilson Bulletin 87:456-466.

Mian, A. (1998). On biology of houbara bustard (Chlamydotis undulata macqueenii) in Balochistan, Pakistan: Breeding. Punjab University Journal of Zoology 13:65-78.

Miller, D. A., J. B. Grand, T. F. Fondell, and R. M. Anthony (2007). Optimizing nest survival and female survival: Consequences of nest site selection for Canada Geese. The Condor 109:769780.

Newton, I. (1991). Habitat variation and population regulation in sparrowhawks. Ibis 133:76-88.

R Development Core Team (2016). R: A Language and Environment for Statistical Computing. R Foundation for Statistical Computing, Vienna, Austria.

Scott, P. E., T. L. DeVault, R. A. Bajema, and S. L. Lima (2002). Grassland vegetation and bird abundances on reclaimed Midwestern coal mines. Wildlife Society Bulletin 30:10061014.

Skeel, M. A. (1983). Nesting success, density, philopatry, and nest-site selection of the Whimbrel (Numenius phaeopus) in different habitats. Canadian Journal of Zoology 61:218-225.

Tieleman, B. I., H. J. Van Noordwijk, and J. B. Williams (2008). Nest site selection in a hot desert: Trade-off between microclimate and predation risk. The Condor 110:116-124.

Tsellarius, A. Y., Y. G. Men'shikov, and E. Y. Tsellarius (1995). Spacing pattern and reproduction in Varanus griseus of western Kyzylkum. Russian Journal of Herpetology 2:153165.

Webb, S. L., C. V. Olson, M. R. Dzialak, S. M. Harju, J. B. Winstead, and D. Lockman (2012). Landscape features and weather influence nest survival of a ground-nesting bird of conservation concern, the Greater Sage-Grouse, in human-altered environments. Ecological Processes 1:4.

White, G. C., and K. P. Burnham (1999). Program MARK: Survival estimation from populations of marked animals. Bird Study 46:S120-S139.

Whittingham, M. J., R. D. Swetnam, J. D. Wilson, D. E. Chamberlain, and R. P. Freckleton (2005). Habitat selection by yellowhammers Emberiza citrinella on lowland farmland at two spatial scales: Implications for conservation management. Journal of Applied Ecology 42:270-280.

Yanes, M., J. Herranz, and F. Suárez (1996). Nest microhabitat selection in larks from a European semi-arid shrub-steppe: The role of sunlight and predation. Journal of Arid Environments 32:469-478.

Yang, W.-K., J.-F. Qiao, O. Combreau, X.-Y. Gao, and W.-Q. Zhong (2003). Breeding habitat selection by the houbara bustard Chlamydotis [undulata] macqueenii in Mori, Xinjiang, China. Zoological Studies 42:470-475.

\section{APPENDIX}

\section{Nest Outcome Classification from Field Signs}

Successful hatching (at least one egg hatched) was confirmed through direct observations of at least one freshly hatched chick in the nest scrape (or just next to it) for half of the successful nests monitored without nest camera $(n=26)$. For the remaining successful nests, field signs of hatching were very small eggshell fragments inside the nest scrape $(n=17)$, and sometimes $(n=8)$ chick footprints could also be visible in and around the scrape, depending on the substrate (not always visible if the scrape was on clay) and the weather conditions subsequent to hatching (wind and/or rain). Nest predation could be attributed to 3 different predators, based on different field signs: desert monitor (Varanus griseus) left footprints, tail marks, and/or claw marks, along with a scrape containing large eggshell fragments and/or congealed yolk and no surviving eggs (data from nest temperature loggers would indicate incubation ended during the middle of the day in these events); signs of fox (Vulpes vulpes or $V$. corsac) predation were an empty clean scrape with variably present footprints and sometimes scat, typically occurring during the night or rarely the early morning (confirmed by temperature logger data); and hedgehog (Paraechinus hypomelas or Hemiechinus auritus) predation signs included eggs pushed from the scrape and left with a small hole in the side and their contents drained. 

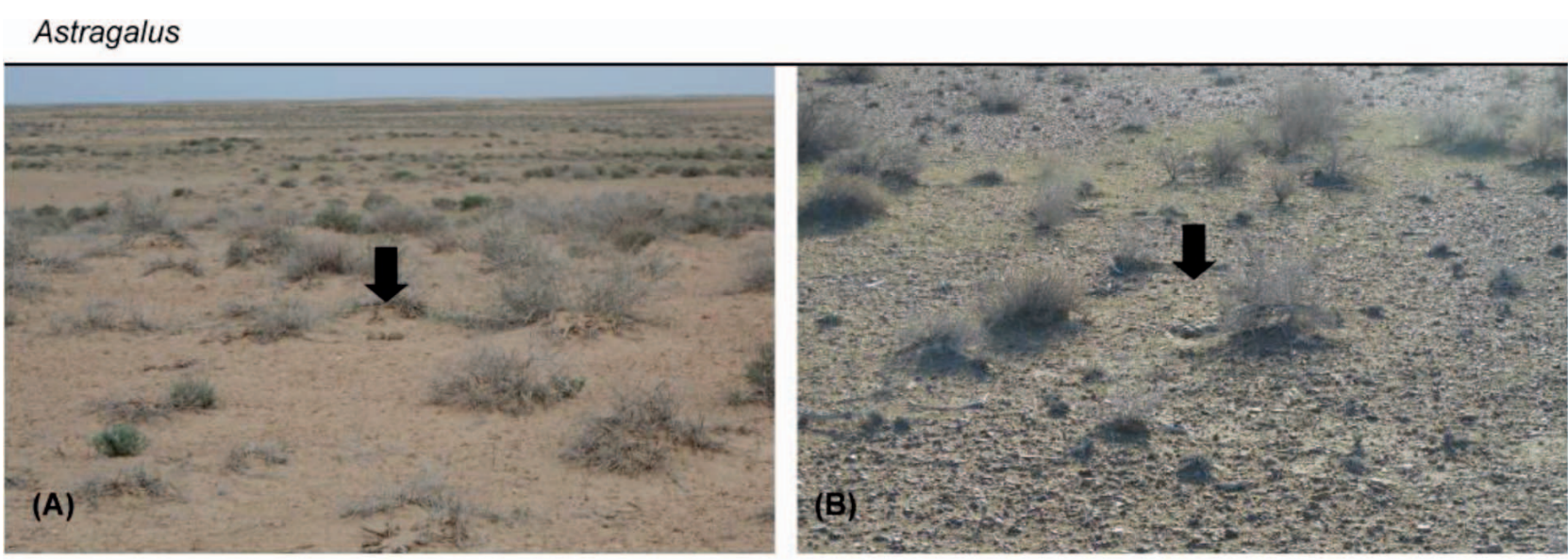

\section{Salsola arbuscula}
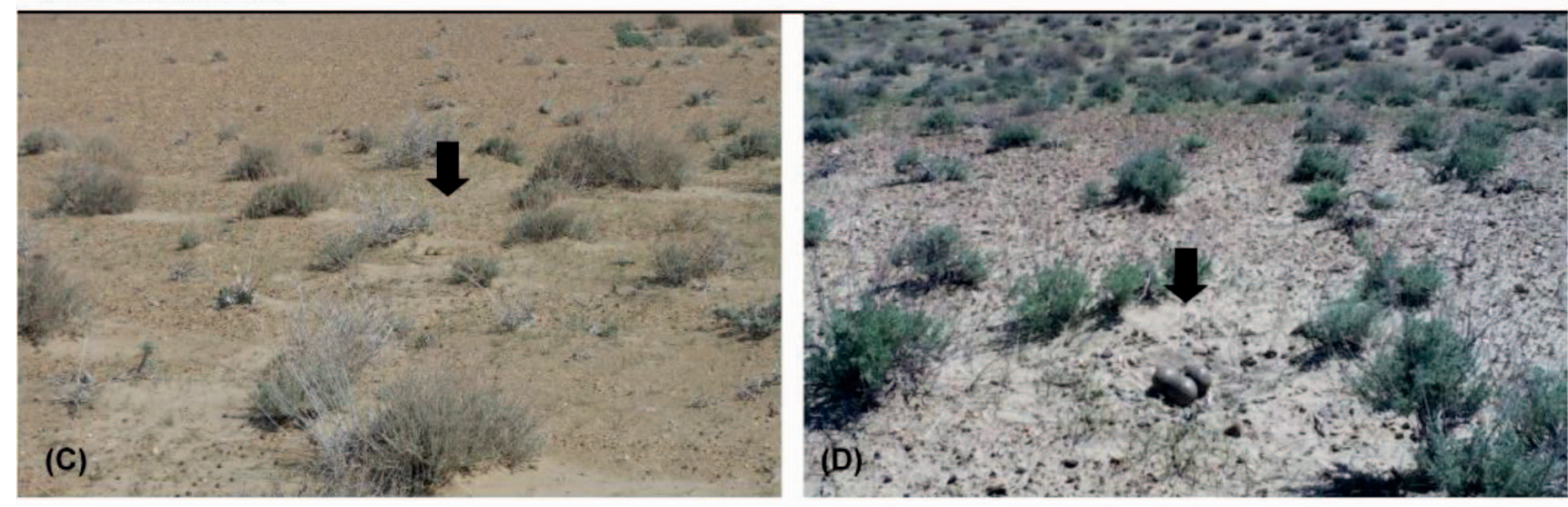

\section{Salsola rigida}
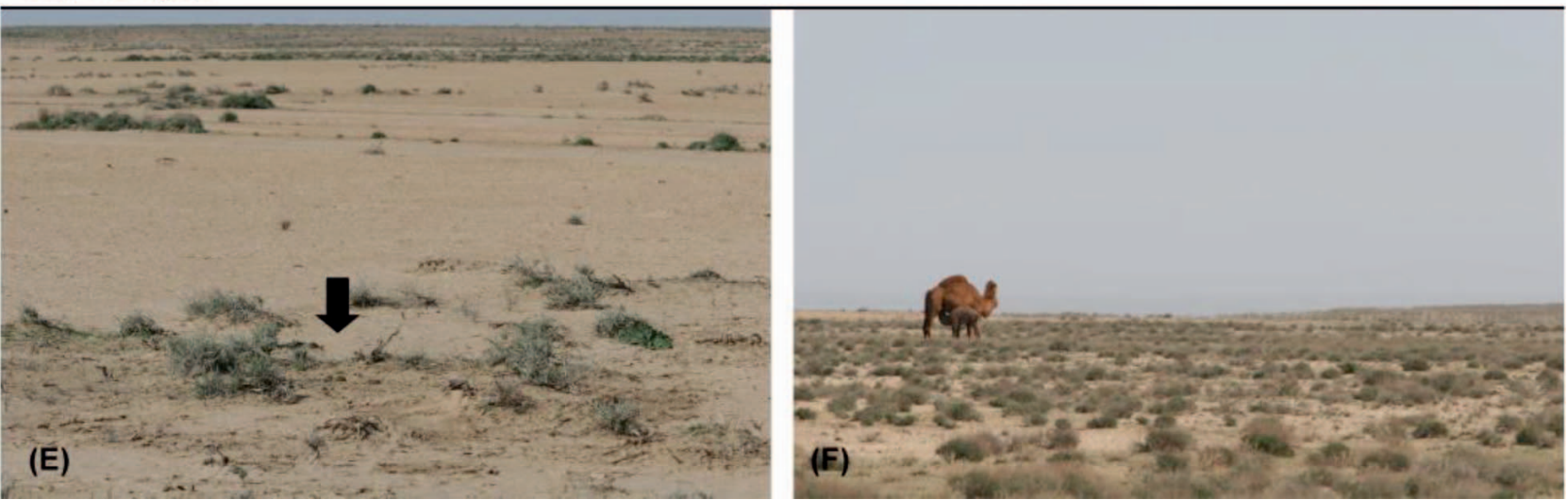

APPENDIX FIGURE 5. Examples of Asian Houbara nesting habitats, defined according to the composition of shrub species assemblages, in a heterogeneous semiarid landscape of the Kyzylkum Desert in Uzbekistan. Panels show nests in situ and examples of each shrub assemblage: (A-B) Astragalus, (C-D) Salsola arbuscula, and (E-F) S. rigida; black arrows indicate the location of nests. 
APPENDIX TABLE 1. Variance in vegetation structure at Asian Houbara nests and control sites, considering 2 scales, "nest area" (mean shrub height and mean shrub frequency; $50 \mathrm{~m}$ radius around nest) and "nest scrape" (concealment index; $2 \mathrm{~m}$ radius from center of scrape), across 3 shrub assemblages: Astragalus, Salsola arbuscula, and S. rigida. Shown are sample sizes and results of Levene's tests comparing variance in measures of vegetation structure for $(A)$ nests compared to controls, separately within each shrub assemblage (one-tailed test of a priori hypothesis that variance is less across nests than across controls); and for (B) controls and $(C)$ nests, each compared between different shrub assemblages (2-tailed tests of null hypothesis that variance is similar between pairs of shrub assemblages): ${ }^{* * *} P<0.001,{ }^{* *} P<0.01,{ }^{*} P<0.05$, nonsignificant (ns) $P>0.05$.

\begin{tabular}{|c|c|c|c|c|c|c|c|c|}
\hline \multirow[b]{3}{*}{ Taxa } & \multirow{3}{*}{$\begin{array}{l}\text { Number } \\
\text { of controls }\end{array}$} & \multirow{3}{*}{$\begin{array}{l}\text { Number } \\
\text { of nests }\end{array}$} & \multicolumn{4}{|c|}{ Nest area scale } & \multirow{2}{*}{\multicolumn{2}{|c|}{$\begin{array}{l}\text { Nest scrape scale } \\
\text { Concealment index }\end{array}$}} \\
\hline & & & \multicolumn{2}{|c|}{ Shrub height } & \multicolumn{2}{|c|}{ Shrub frequency } & & \\
\hline & & & $F$ & $P$ & $F$ & $P$ & $F$ & $P$ \\
\hline \multicolumn{9}{|c|}{ (A) Nests compared to controls, within shrub assemblage } \\
\hline Astragalus & 97 & 91 & 17.633 & $* * *$ & 7.162 & ** & 3.123 & * \\
\hline Salsola arbuscula & 57 & 96 & 10.063 & $* * *$ & 0.186 & ns & 18.977 & *** \\
\hline Salsola rigida & 40 & 23 & 3.327 & * & 0.189 & ns & 1.543 & $\mathrm{~ns}$ \\
\hline \multicolumn{9}{|c|}{ (B) Controls, compared between shrub assemblage } \\
\hline Astragalus vs. S. arbuscula & 154 & & 1.81 & ns & 0.22 & ns & 1.60 & ns \\
\hline Astragalus vs. S. rigida & 137 & & 1.28 & ns & 2.02 & ns & 0.82 & ns \\
\hline S. arbuscula vs. S. rigida & 97 & & 0.02 & ns & 2.68 & ns & 0.00 & ns \\
\hline \multicolumn{9}{|c|}{ (C) Nests, compared between shrub assemblage } \\
\hline Astragalus vs. S. arbuscula & & 187 & 1.20 & ns & 15.22 & *** & 3.03 & ns \\
\hline Astragalus vs. S. rigida & & 114 & 0.19 & ns & 0.01 & ns & 0.20 & ns \\
\hline S. arbuscula vs. S. rigida & & 119 & 0.02 & ns & 4.34 & * & 0.27 & ns \\
\hline
\end{tabular}

APPENDIX TABLE 2. Differences in vegetation structure available to Asian Houbara at control sites and nests, considering 2 scales, "nest area" (mean shrub height and mean shrub frequency; 50 m radius around nest) and "nest scrape" (concealment index; $2 \mathrm{~m}$ radius from center of scrape), compared between 3 shrub assemblages: Astragalus, Salsola arbuscula, and S. rigida. Shown are sample sizes and results of pairwise comparisons of means of each vegetation structure variable using Bonferroni corrections at (A) controls, using generalized linear models; and at (B) nests, using generalized linear mixed-effect models to accommodate female identity; in all models Bonferroni corrections for multiple comparisons were applied: ${ }^{* *} P<0.001,{ }^{* *} P<0.01,{ }^{*} P<0.05$, nonsignificant (ns) $P>0.05$.

\begin{tabular}{|c|c|c|c|c|c|c|c|c|c|c|}
\hline \multirow[b]{3}{*}{ Taxa } & \multirow{3}{*}{$\begin{array}{l}\text { Number of } \\
\text { controls } \\
\text { or nests }\end{array}$} & \multicolumn{6}{|c|}{ Nest area scale } & \multirow{2}{*}{\multicolumn{3}{|c|}{$\begin{array}{l}\text { Nest scrape scale } \\
\text { Concealment index }\end{array}$}} \\
\hline & & \multicolumn{3}{|c|}{ Shrub height } & \multicolumn{3}{|c|}{ Shrub frequency } & & & \\
\hline & & df & $t$ & $P$ & df & $t$ & $P$ & df & $t$ & $P$ \\
\hline \multicolumn{11}{|l|}{ (A) Controls } \\
\hline Astragalus vs. S. arbuscula & 152 & 190 & 6.91 & $* * *$ & 190 & -3.63 & $* * *$ & 190 & -0.10 & ns \\
\hline Astragalus vs. S. rigida & 135 & 190 & 6.45 & $* * *$ & 190 & 1.47 & ns & 190 & 0.58 & ns \\
\hline $\begin{array}{l}\text { S. arbuscula vs. S. rigida } \\
\text { (B) Nests }\end{array}$ & 95 & 190 & 0.37 & ns & 190 & 4.29 & $* * *$ & 190 & 0.62 & ns \\
\hline Astragalus vs. S. arbuscula & 150 & 180 & 7.20 & $* * *$ & 164 & -4.10 & $* * *$ & 180 & 0.90 & ns \\
\hline Astragalus vs. S. rigida & 86 & 180 & 5.21 & $* * *$ & 164 & 1.69 & ns & 180 & 1.20 & ns \\
\hline S. arbuscula vs. S. rigida & 94 & 180 & 1.01 & ns & 164 & 4.21 & $* * *$ & 180 & 0.67 & $\mathrm{~ns}$ \\
\hline
\end{tabular}

